\title{
Distributional analysis of rural-urban household healthcare expenditure differentials in developing countries: evidence from Ghana
}

Samuel Ampaw

School of Economics, University of Nottingham Ningbo China, Ningbo, China, and

Edward Nketiah-Amponsah, Frank Agyire-Tettey and

Bernardin Senadza

Department of Economics, University of Ghana, Accra, Ghana
Distributional analysis of rural-urban

Received 23 July 2019 Revised 19March 2020 Accepted 25 April 2020

\begin{abstract}
Purpose - Equity in access to and use of healthcare resources is a global development agenda. Policymakers' knowledge of the sources of differences in household healthcare spending is crucial for effective policy. This paper aims to investigate the differences in the determinants of household healthcare expenditure across space and along selected quantiles of healthcare expenditure in Ghana. The determinants of rural-urban healthcare expenditure gap are also explored.

Design/methodology/approach - Data was obtained from the sixth round of the Ghana Living Standards Survey (GLSS 6) conducted in 2013. An unconditional quantile regression (UQR) and a decomposition technique based on UQR, adjusted for sample selection bias, were applied.

Findings - The results indicate that differences in the determinants of household healthcare expenditure across space and along quantiles are driven by individual-level variables. Besides, the rural-urban health expenditure gap is greatest among households in the lower quantiles and this gap is largely driven by differences in household income per capita and percentage of household members enrolled on health insurance policies.

Originality/value - The findings show that there are differences in the determinants of household health expenditure along with the income distribution, as well as between rural and urban localities, which would call for targeted policies to address these inequalities.
\end{abstract}

Keywords Household healthcare expenditure, Rural-urban inequality,

Unconditional quantile regression, Healthcare financing policy, Developing countries, Ghana

Paper type Research paper

\section{Introduction}

Public health spending is important to improving health outcomes and human capital development. Improved health outcomes have positive consequences for economic growth and individual welfare. For instance, Murthya and Okunadeb (2009) argue that increased healthcare expenditure has a positive effect on labour efficiency, quality of life and welfare. They further credit improved health outcomes to increases in healthcare spending. Anyanwu and Erhijakpor (2009) also find that health expenditures have a negative impact on health outcomes such as infant and under-five mortality in Africa. Similar findings were made by Ashiabi et al. (2016) and Arthur and Oaikhenan (2017). Novignon et al. (2015) observe that population health status relates positively with labour force participation and

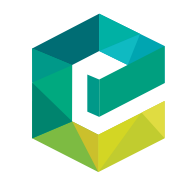

International Journal of Development Issues C Emerald Publishing Limited DOI $10.1108 /$ IJDI-07-2019-0126 
contributes to national output. Yet, public health spending continues to be low in developing countries compared with developed countries. The OECD countries alone contribute about $85 \%$ of the world's total healthcare spending, while Africa's share is only 3\% (Novignon et al., 2012). The burden of financing health needs in many developing countries, Ghana inclusive, therefore, falls on the households largely (Ottersen et al., 2017).

Malik and Syed (2012) disclose that in 2005, out-of-pocket (OOP) healthcare payment was $67 \%$ of the total healthcare expenditure in Pakistan, while the corresponding figure was $45 \%$ in Ghana (Akazili et al., 2014). Molla et al. (2017) also report that OOP healthcare payments by households contribute up to $63 \%$ of total health expenditure in Bangladesh. In Nigeria, despite the introduction of the National Health Insurance Scheme (NHIS), household healthcare financing accounts for more than $60 \%$ of Nigeria's total healthcare spending (Olasehinde and Olaniyan, 2017), the existence of an NHIS notwithstanding. Against this backdrop, studies on the factors that motivate household healthcare spending in developing countries are justified. Molla et al. (2017) opine that such studies are useful for effective policy on the healthcare financing system.

Typifying the situation in several developing countries, a majority of deprived persons in Ghana reside in the country's rural areas. Although Ghana's national average poverty incidence is $24 \%$ as at 2013 , rural households account for $78 \%$ of the poor with a higher than national average poverty incidence of 38\% (Ghana Statistical Service, 2014). In addition, rural households in Ghana are reported to have less access to healthcare compared to their urban counterparts (ibid). Owing to the complex relationship between poverty and health, Peters et al. (2008) and O'Donnell (2007) posit that the poor, most of whom reside in rural areas of developing countries, suffer most from ill-health.

The extant literature affirms the rural-urban inequality in the access to and utilisation of healthcare resources (inter alia, Hartley, 2004; Ziller et al., 2006; Donfouet et al., 2011; Ghana Statistical Service, 2014; Lee et al., 2014; Olasehinde and Olaniyan, 2017; Molla et al., 2017). However, not much is reported about the sources of these differences. Meanwhile, inequity in the use of healthcare resources has been identified as a hindrance to the achievement of universal health coverage, even though it remains central to the achievement of the sustainable development agenda (WHO, 2010; Ottersen et al., 2017). Using the most recent and nationally representative household-level data for Ghana, this paper seeks to contribute to the present literature in two ways. Firstly, it seeks to examine the differences in the determinants of healthcare expenditure among rural and urban households. Owing to the possibility of the drivers of healthcare spending varying along with the distribution of household healthcare expenditure, we used the unconditional quantile regression (UQR) technique. Secondly, the paper explores the determinants of the rural-urban household healthcare expenditure gap along the 10th, 25th, 50th, 75th and 90th quantiles of healthcare expenditure using the UQR-based decomposition technique. To obtain consistent parameter estimates from the UQR, we followed the Heckman two-step procedure to correct for sample selection bias (Heckman, 1979). To the best of the authors' knowledge, this is a novel contribution to literature. The rest of the paper is organised as follows. Section 2 presents a brief exposition on healthcare financing in Ghana. Section 3 is on related to the empirical literature. Section 4 presents the data and methods. Results are discussed in Section 5 and finally, Section 6 concludes with policy recommendations.

\section{Synopsis of healthcare financing in Ghana}

Ghana's health financing system has seen several phases. According to Akazili et al. (2014), the system has over the years been modelled after the political ideology of the ruling government. Prior to independence, the system of OOP payments for healthcare was 
practiced. However, the governments in the post-independence era provided free healthcare for the citizenry. In the early 1980s, stemming from the Structural Adjustment Programme, the user fee OOP payment/cash-and-carry) system was reinstated. This was because the taxfinanced system encountered quality and sustainability challenges. Bagnoli (2017) reports that the user fee system resulted in a drop in utilisation of healthcare by about $25 \%$ among rural residents, elderly, women and the poor. To address the challenges associated with the user fee system, community-based insurance schemes were introduced in the 1990s. These pooled risks and improved access to healthcare resources. The community-based insurance schemes motivated the NHIS, which was introduced in the year 2003. This scheme is among the first in sub-Saharan Africa (Aryeetey et al., 2016a).

Nketiah-Amponsah and Arthur (2013) submit that in 2005, implementation of the scheme gave rise to increased outpatient utilisation from 0.6 million to 16.9 million. Furthermore, Aryeetey et al. (2016b) posit that enrollment on the NHIS reduces OOP payments on health, protects against catastrophic expenditures and alleviates poverty. Even though the NHIS was designed to be pro-poor, enrolment on it is currently impeded by poverty (Jehu-Appiah et al., 2011; Dixon et al., 2011; Akazili et al., 2014; Ghana Statistical Service, 2014; Alhassan et al., 2016). Bagnoli (2017) postulates that the scheme being pro-rich and pro-urban raises equity concerns. Though the NHIS is still in operation, OwusuSekyere and Bagah (2014) disclose that OOP payments on healthcare in Ghana have reemerged in recent times partly due to delayed reimbursement to NHIS-accredited health facilities. This assertion is supported by the Ghana Statistical Service (2014), which reports that more than half of OOP payments, including cost of consultation, medicines and hospital admissions, are financed by households.

\section{Related literature}

\subsection{Determinants of healthcare expenditure}

Few cross-sectional studies have examined the determinants of household healthcare expenditure in developing countries (inter alia, Onwujekwe et al., 2010; You and Kobayashi, 2011; Yildirim et al., 2011; Malik and Syed, 2012; Molla et al., 2017; Olasehinde and Olaniyan, 2017; Mahumud et al., 2017). These studies focus more on the mean pattern of health expenditure. For instance, while You and Kobayashi (2011) adopted the Heckman selection model to correct for selection bias in their study, which used data from the 2004 China Health and Nutrition Survey, Onwujekwe et al. (2010) applied logistic regression to model data collected from six rural and urban areas (three each) in south-east Nigeria. Even though averages are good, distribution is also important.

Despite the identified shortcomings, the existing literature emphasises the importance of household-level and individual-level variables in influencing household healthcare expenditures. In a recent study of household healthcare expenditure in Nigeria, Olasehinde and Olaniyan (2017) find age, religion, education, income, household size and household headship to be significant determinants. Further findings are that though household characteristics are more significant among rural households, individual characteristics of the household head, including marital status and employment, have varying effects in both rural and urban areas. Olasehinde and Olaniyan (2017) used the Engel curve technique, which is based on the ordinary least squares method, to model data from the 2010 Harmonised Nigeria Living Standards Survey. Like most of the extant studies, the study by Olasehinde and Olaniyan (2017) fails to correct for potential selection bias besides the fact that the identified determinants are likely to vary along with the distribution of healthcare. Even though Molla et al. (2017) examined the determinants of high household healthcare expenditure in Bangladesh using multiple linear regression techniques, in the present paper,

Distributional analysis of rural-urban

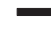

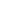


we contribute further to the literature by applying the UQR approach to explore the determinants of household health expenditure along the 10th, 25th, 50th, 75th and 90th quantiles of healthcare expenditure in both rural and urban areas of Ghana using relatively more recent data.

\subsection{Rural-urban inequities in healthcare}

Huge and widening gaps in terms of welfare, measured by consumption, are reported between urban and rural areas of most developing economies. According to Go et al. (2007), this unequal distribution of economic and social outcomes, including access to health contributes substantially to the overall inequality in sub-Saharan Africa. The rural-urban inequities in the distribution of household consumption have been fairly studied (inter alia, Nguyen et al., 2007; Agyire-Tettey et al., 2017; Azam, 2017).

Using the UQR-based decomposition technique, Agyire-Tettey et al. (2017) examined the rural-urban consumption gap in Ghana. They attribute the gap in consumption between rural and urban households to disparities in the returns to socioeconomic factors. Azam (2017) used the same technique to explore the rural-urban welfare gap in India. They submit that India's consumption gap results from urban advantages in socioeconomic characteristics; adding that the disparity in education contributes most to the established rural-urban consumption gap in India. Nguyen et al. (2007) made similar findings for Vietnam using the same empirical approach. They add that the factors accounting for the rural-urban inequality in consumption -such as education, ethnicity and age- vary across the distribution of consumption expenditures. Though healthcare is a component of consumption and the rural-urban inequalities in the access to and utilisation of healthcare resources continue to broaden, the literature on the rural-urban gap in the consumption of healthcare in developing countries is non-existent to the best of the authors' knowledge.

From the above discussions, it is evident that existing studies are biased towards exploring the differences in the determinants of household healthcare expenditures in rural and urban areas without explaining the determinants of the healthcare consumption gaps. In addressing this lacuna in the literature, the present study investigates the sources of the rural-urban healthcare expenditure gaps along with the distribution of household healthcare expenditure.

\section{Methods}

\subsection{Data}

We use data from the sixth round of the Ghana Living Standards Survey (GLSS 6). The survey was conducted by the Ghana Statistical Service from 18 October 2012 to 17 October 2013. Technical support was provided by the World Bank as the Ghana Living Standard Survey (GLSS) epitomises the World Bank's Living Standards Measurement Survey. The GLSS follows a two-stage sampling method. In the first stage, enumeration areas were randomly selected. The selection is done by means of probabilities. These probabilities are proportional to the proportions of the population. Subsequently, households are systematically selected based on the principal sampling units. Despite the selection of a nationally representative sample of 18,000 households in 1,200 enumeration areas, 16,772 households were successfully interviewed in the GLSS6 (Ghana Statistical Service, 2014). This resulted in a response rate of 93.2\%. The GLSS6 provides information on individual and household characteristics.

\subsection{Outcome variables}

The GLSS6 collected data on the total household spending on healthcare (tothlthexp) in local currency units (Ghanaian cedi, GHS). This total covered spending on medical products, appliances and equipment, outpatient services and hospital services (hospitalisation). Then, 
there is potential selectivity bias, as sick respondents tend to spend more on health. However, this is partly addressed by the inclusion of health status as a control variable. Per capita, household healthcare expenditure (pchlthexp) was computed from the total (tothlthexp). Given that the variable (pchlthexp) is right-skewed, we applied the inverse hyperbolic sine transformation (IHST) technique to normalise it. Seven households out of the original 16,772 households were dropped due to missing information about their total healthcare expenditure. Of the remaining 16,765 households, 7,373 reported incurring no cost on healthcare over the survey period while the remaining 9,392 indicated otherwise. The healthcare spending status, a binary variable, was used to model the decision by households in Ghana to spend on healthcare. The goal was to enable the computation of the inverse mills variable[1] used in correcting for potential sample selection biases. All the sampled households were used[2]. On the other hand, in exploring the determinants of healthcare expenditures among households in rural and urban households, as well as investigating the sources of the rural-urban healthcare expenditure gaps along the 10th, 25th, 50th, 75th and 90th quantiles, only the sampled households with observed healthcare expenditures were used. The description and measurement of the outcome variables are presented in Table 1.

\subsection{Explanatory variables}

With recourse to the literature, the individual and household characteristics selected to explore the rural-urban household healthcare expenditure differentials in Ghana include age, sex, employment type, educational attainment, income, ethnicity, religion, health status, health insurance. Due to the high level of nonresponse with regards to some selected variables in the data, the total number of interviewed households further dropped from 16,765 to 16,514 . Of the 16,514 households used for the study, 9,254 reported spending on healthcare albeit 7,260 indicated otherwise. The description and measurement of the selected explanatory variables are presented in Table 2.

\subsection{Estimation technique}

A UQR, adjusted for sample selection bias was used to achieve the first objective of the study. Following Heckman's two-step procedure (Heckman, 1979), we first obtained an inverse mills ratio (IMR) (sample selection correction term) based on a logistic regression model. This variable was then used as an independent variable in the UQR. The choice of the UQR over the conditional quantile regression is merely because of the interpretational advantage of the former over the latter. The healthcare expenditure linear regression model used is specified as follows:

$$
Y_{j i}=\text { pchlthexp }_{j i}=\beta_{j 0}+\sum_{q=1}^{Q} \beta_{j q} X_{j i q}+\varepsilon_{j i}
$$

where; $p c h l t h \exp _{j i}\left(y_{j i}\right)$ is the IHST of healthcare expenditure per capita of household $i$, located in area $j$ (rural or urban); $X_{j i q}$ denotes the vector of explanatory variables of household $i$ in

\begin{tabular}{ll}
\hline Outcome variables & Description and measurement \\
\hline $\begin{array}{l}\text { Healthcare expenditure } \\
\text { (pchlthexp) }\end{array}$ & IHST of household healthcare expenditure per capita: in GHS \\
$\begin{array}{l}\text { Spends on health (hlth_spends) } \\
\text { Healthcare spending status: } 1 \text { = household spends on healthcare, } \\
\text { otherwise } 0\end{array}$
\end{tabular}

\section{Distributional analysis of rural-urban}

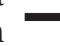




\section{IJDI}

\begin{tabular}{|c|c|}
\hline $\begin{array}{l}\text { Explanatory } \\
\text { variables }\end{array}$ & Description and measurement \\
\hline & Head characteristics \\
\hline Age/100 & Age of household head: number of years/100 \\
\hline $\mathrm{Age}^{2}$ & Age square: square of the age of household head \\
\hline Female & Sex of household head: $1=$ female; male $=0$ \\
\hline Employment & $\begin{array}{l}\text { Employment type: } 1 \text { = other employment (domestic employment/family } \\
\text { employment/apprentiship/others) }{ }^{+} ; 2=\text { salaried/wage employment; } 3=\text { self- } \\
\text { employment }\end{array}$ \\
\hline Educational & $\begin{array}{l}\text { Educational attainment: } 1=\text { no formal education }{ }^{+} ; 2=\text { basic; } 3=\text { at least } \\
\text { secondary }\end{array}$ \\
\hline Christian & Religious affiliation: $1=$ Christianity; $0=$ no religion, Islam, traditional, etc. \\
\hline Akan & $\begin{array}{l}\text { Ethnic affiliation: } 1=\text { Akan; } 0=\text { otherwise } \\
\text { Household characteristics }\end{array}$ \\
\hline Income & Log of real household income per capita (GHS) \\
\hline$\%$ ill & Percentage of ill/injured household members in the past $24 \mathrm{~h}$ \\
\hline$\%$ insured & Percentage of medically insured household members \\
\hline$\%<18$ years & Percentage of household members below 18 years. \\
\hline$\%>64$ years & Percentage of household members over 64 years. \\
\hline Urban & Place of residence: 1 = urban; $0=$ rural \\
\hline & Variables for satisfying the exclusion principle in the Heckman approach \\
\hline North & $\begin{array}{l}\text { Region of residence: } 1=\text { three northern regions (northern, upper east and upper } \\
\text { west regions), otherwise } 0\end{array}$ \\
\hline Ecological zone & $\begin{array}{l}\text { Ecological zone of residence: } 1=\text { coastal zone, } 2 \text { = forest zone, } 3=\text { Savannah } \\
\text { zone, } 4 \text { = Greater Accra Metropolitan Assembly (GAMA) }\end{array}$ \\
\hline
\end{tabular}

area $j . \beta$ jq represent the vector of parameters. Subsequently, we applied the UQR-based decomposition technique proposed by Fortin et al. (2011) to explain the household healthcare expenditure gap in rural vs urban Ghana. This approach decomposed the gap into the selected explanatory variables. According to Fortin et al. (2011), the UQR technique is an extension of the Oaxaca-Blinder (OB) mean-based decomposition technique. From equation (1), the OB decomposition model is specified as follows.:

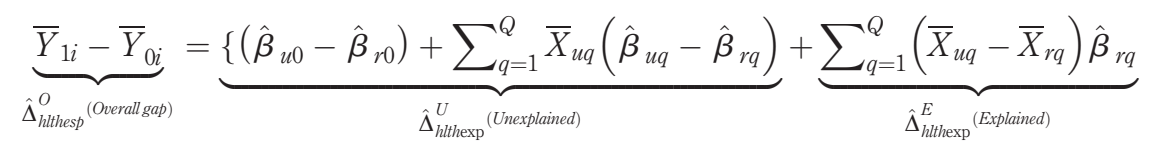

where; $\hat{\boldsymbol{\beta}}_{j 0}$ and $\hat{\boldsymbol{\beta}}_{j q}$ denote the estimated intercept and parameters for the respective regression models in $j$ (urban, rural). Equation (2) provides estimates for the overall ruralurban household healthcare expenditure gap, which is decomposed into explained and unexplained effects at the mean. It also provides estimates to depict the contribution of each covariate to the observed gap.

\section{Results and discussion}

\subsection{Summary statistics}

Figure 1 shows the kernel density of household healthcare expenditure per capita for rural and urban households in Ghana based on data from the GLSS6. The figure depicts that in the year under review, the urban density lies rightward of the rural density. This suggests that on 
average urban households spend more on the health of their members than rural households. This is confirmed by Table 3 , which reports summary statistics of the selected variables by place of residence (rural vs urban) for 3,846 urban households and 5,410 rural households that spent on healthcare and suggest that on average urban households spent more on health than rural households. This difference is statistically significant. Urban households are shown to have relatively younger members, a greater proportion of female heads, heads in salaried/wage and domestic/family employments head with higher education and heads who are Christians and Akans.[3] Additionally, urban households have higher income per capita and more medically insured members than their counterparts in rural areas. Conversely, more rural households than the urban households in our sample have greater percentages of ill members and older dependants (persons over 64 years). Aside from basic education and the percentage of household members who are younger than 18 years, all other variables differ statistically.

\subsection{Determinants of healthcare expenditure}

Table 4 presents the coefficient estimates from the UQR of the determinants of household healthcare expenditure in rural vs urban Ghana at the 10th, 25th, 50th, 75th and 90th quantiles. The IMR is significant at all the quantiles, suggesting the presence of selection bias in household healthcare expenditure decisions. The household-level variables including household income and the percentage of ill and medically insured household members - proved to be the most significant determinants across space and along the selected quantiles. These variables are found to have similar effects on healthcare expenditure. The other two household-level variables, the percentage of household members

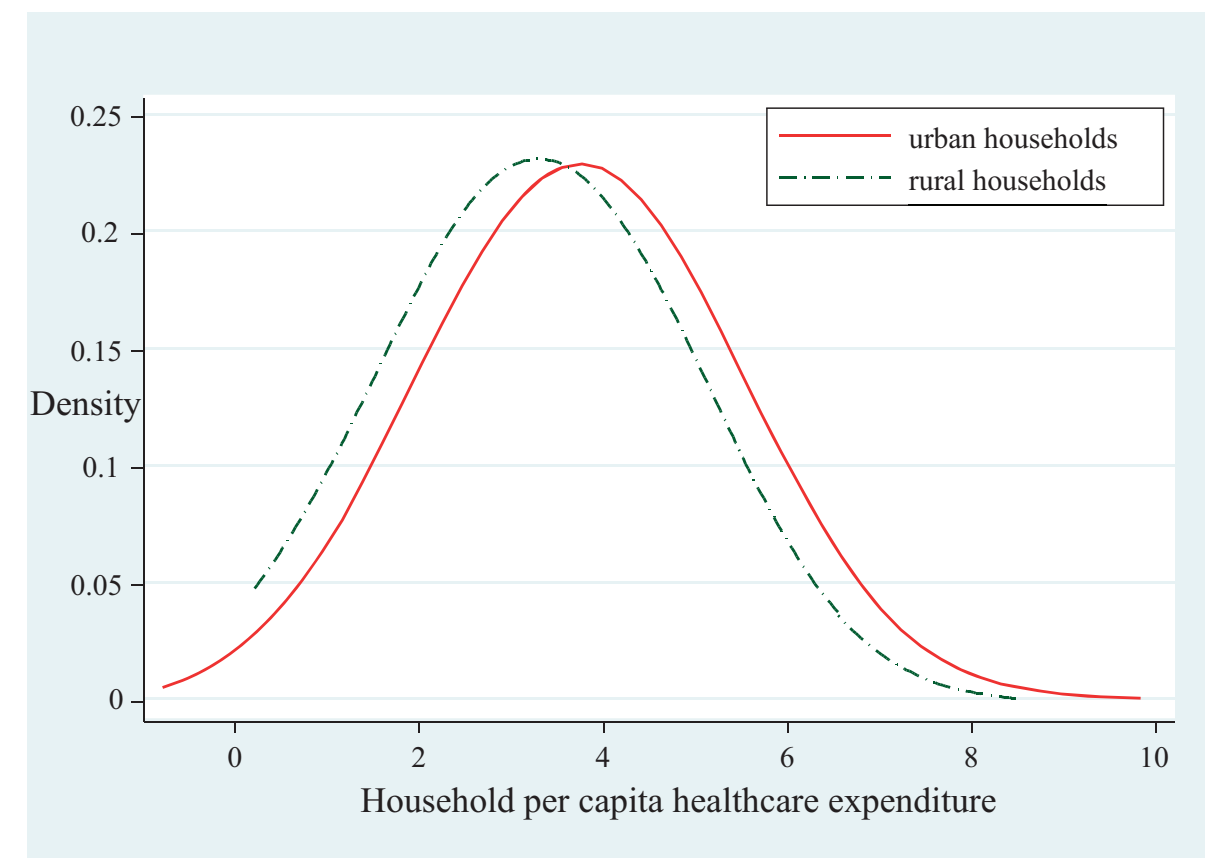

Source: Computed by authors from GLSS 6, 2012/2013
Distributional analysis of rural-urban
Figure 1. Rural-urban inequality in healthcare expenditure in Ghana, 2012/2013 


\begin{tabular}{|c|c|c|c|c|c|c|c|}
\hline \multirow{2}{*}{\multicolumn{2}{|c|}{ Variables }} & \multicolumn{2}{|c|}{ Rural } & \multicolumn{2}{|c|}{ Urban } & \multirow{2}{*}{$\begin{array}{l}\text { Mean } \\
\text { Difference }\end{array}$} & \multirow[t]{2}{*}{$p$-value } \\
\hline & & Mean & $\mathrm{SE}$ & Mean & $\mathrm{SE}$ & & \\
\hline & Healthcare expenditure & 3.45 & 0.04 & 3.84 & 0.04 & $-0.39 * * *$ & 0.00 \\
\hline & Age & 47.55 & 0.32 & 44.45 & 0.34 & $3.10^{* * * *}$ & 0.00 \\
\hline & Female & 0.26 & 0.01 & 0.35 & 0.01 & $-0.09 * * *$ & 0.00 \\
\hline & Christian & 0.67 & 0.02 & 0.77 & 0.02 & $-0.10^{* * * *}$ & 0.00 \\
\hline & Akan & 0.47 & 0.02 & 0.53 & 0.2 & $-0.06^{*}$ & 0.06 \\
\hline & Other employments & 0.04 & 0.00 & 0.07 & 0.01 & $-0.03^{* * * *}$ & 0.00 \\
\hline & Salaried/wage employment & 0.12 & 0.01 & 0.35 & 0.01 & $-0.23 * * *$ & 0.00 \\
\hline & Self-employment & 0.84 & 0.01 & 0.58 & 0.02 & $0.26^{* * *}$ & 0.00 \\
\hline & No education & 0.47 & 0.02 & 0.25 & 0.02 & $0.22 * * *$ & 0.00 \\
\hline & Basic education & 0.44 & 0.01 & 0.47 & 0.01 & -0.02 & 0.19 \\
\hline & At least secondary education & 0.08 & 0.01 & 0.28 & 0.02 & $-0.20^{* * * *}$ & 0.00 \\
\hline & Income & 6.92 & 0.04 & 7.07 & 0.05 & $0.15^{* * * *}$ & 0.01 \\
\hline & $\%$ ill & 15.07 & 0.55 & 13.62 & 0.56 & $1.45^{*}$ & 0.07 \\
\hline & $\%$ insured & 6.91 & 0.60 & 12.53 & 1.03 & $-5.62^{* *}$ & 0.00 \\
\hline & $\%<18$ years & 16.35 & 0.21 & 16.05 & 0.28 & 0.29 & 0.40 \\
\hline Table 3. & $\%>64$ years & 8.34 & 0.41 & 6.17 & 0.40 & $2.17 * * *$ & 0.00 \\
\hline
\end{tabular}

Summary statistics of the selected variables by place of residence
Notes: All but health expenditure, age, income, ill members, health insured, young dependents and old dependents, are in proportions. $\mathrm{SD}=$ standard deviation. $\mathrm{SE}=$ linearised standard errors. Sample weights and clusters used in the estimation of the mean values and SEs

Source: Computed by authors from GLSS 6, 2012/2013

below 18 years and those above 64 years, are, however, significant in the lower (10th and 25 th) and mid (50th) quantiles only. The significant individual-level variables $(p<0.05)-$ comprising employment type, higher education and ethnicity- are found to have differential effects on household healthcare expenditure across space and along the selected quantiles. The results indicate that the differences in the determinants of household healthcare expenditure across space and the selected quantiles exist mainly in the individual-level variables.

Income and ill-health are reported to have positive effects on household healthcare expenditure. You and Kobayashi (2011), Olasehinde and Olaniyan (2017) made similar observations in their study of China and Nigeria, respectively. On average, we find that a percentage change in income results in a 0.158 percentage change in healthcare expenditure in Ghana. The income elasticity of demand for healthcare being positive but less than one presupposes that healthcare is considered a necessity good by both rural and urban households in Ghana. The low-income elasticity reported is plausibly due to the presence of the NHIS in Ghana, which renders the ability to pay a less important determinant of healthcare expenditure. Rous and Hotchkiss (2003), however, report a higher income elasticity of 1.02 for Nepal, using data from 1995/1996. Along the selected quantiles, we find the income elasticity to be greater in the rural sample relative to the urban sample. Olasehinde and Olaniyan (2017) reported the same for rural and urban Nigeria at the mean expenditure. Income as a determinant of household healthcare expenditure is more important in rural areas compared to the urban areas.

Our study further finds that the percentage of medically insured household members is positively associated with household healthcare expenditure. This suggests a complementary relationship between the two variables. A plausible reason for this finding is the fact that health insurance policies in Ghana, the NHIS inclusive, mostly do not cover the entire costs incurred while seeking and obtaining healthcare, and thus, households 


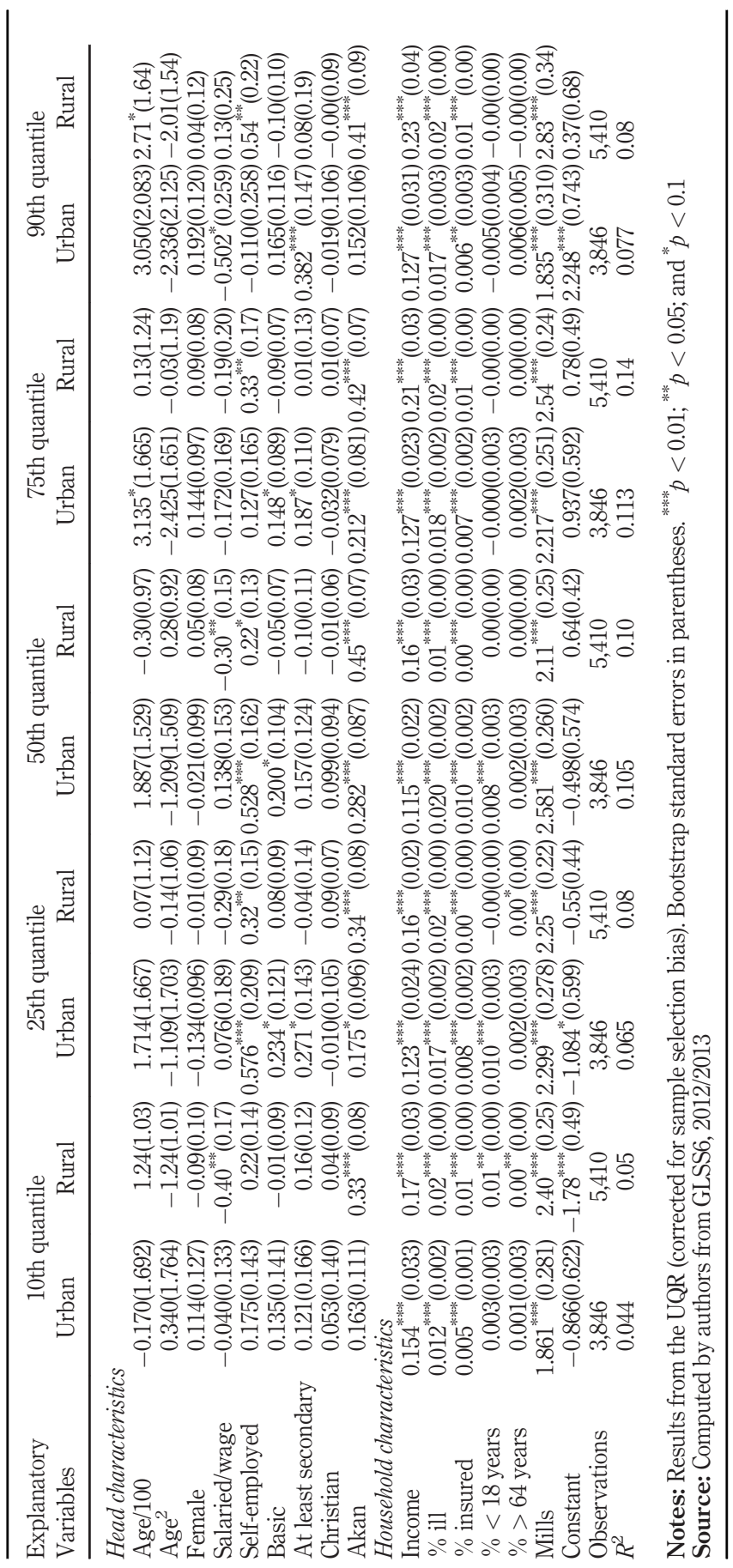


unavoidably are required to incur additional costs. In the NHIS for instance, dialysis and chemotherapy for the treatment of kidney and cancer conditions are not covered by the scheme. Furthermore, as expected, the percentage of dependants (both young and old) is found to have a positive and significant effect on household healthcare expenditure. This is particularly so in the lower and mid quantiles; though varies across space.

Relative to households headed by persons in domestic or family employments or apprenticeships, households headed by persons in paid jobs in rural areas are found to spend less on healthcare. This is particularly so among households in the lowest (10th) and mid (50th) quantiles only. The rationale for this may be that households headed by persons in paid jobs together with their dependents, benefit from paid healthcare by their employers and, hence, tend to spend less on healthcare. Besides, as enrolment in the NHIS is mandatory for public sector employees, households headed by government workers are more likely to be insured and, thus, spend less OOP on healthcare. van der Wielen et al. (2018) highlight the positive correlation between public sector employment and enrolment in the NHIS. Moreover, but for the households in the 10th quantile, both rural and urban households headed by persons in self-employments are found to spend more on healthcare. In the higher quantiles (75th and 90th), self-employment is significant $(\phi<0.05)$ only among rural households.

Finally, though Rous and Hotchkiss (2003) report a negative relationship between higher education and household healthcare spending in Nepal, higher education is found to have a positive effect on higher household healthcare expenditure allocation in urban Ghana. Particularly, the attainment of at least a secondary education variable is reported to be significant $(\phi<0.01)$ in the 90th quantile in the urban sample only. Suggestively, higher education is associated with higher healthcare spending in urban Ghana. This evidence discourages the use of the same healthcare financing policies based on education to address healthcare needs in both rural and urban Ghana.

\subsection{Rural-urban inequality in healthcare expenditure}

Table 5 shows the results from the UQR-based decomposition for the rural-urban healthcare expenditure gap and the determinants of the gap. Similar to the earlier discussion, the significance $(p<0.01)$ of the IMR proposes the presence of selection bias, which when not corrected would result in the inconsistent estimation of the covariates. The total gap is decomposed into explained (endowments/covariate) and unexplained (returns to covariates). The contribution of the covariates to the gap is found to be greater than that of the returns. Moreover, beyond the 25th quantile, the overall gap is found to mimic the trend of the unexplained gap more than the trend in the explained gap (Figure 2). The results in Table 5 indicate that the overall gap in the rural-urban healthcare expenditure is significantly influenced by gaps in both the explained and unexplained factors. Along with the entire distribution of healthcare expenditure, urban households are found to expend more on healthcare than rural households. The observed gap is found to be greatest among the households in the least quantile (10th and 25th) and least among the average spenders (in the 50 th quantile) on healthcare.

Differences in per capita income, percentage of household members enrolled on health insurance policies and ethnic affiliation between rural and urban households proved to contribute most to the rural-urban household healthcare expenditure gap. This is because these variables are found to have significant $(\phi<0.05)$ and positive effects on the household healthcare expenditure gap between rural and urban households in all the quantiles. AgyireTettey et al. (2017) report that though Ghana has experienced impressive economic growth since the 1990s, between-group inequalities remain ubiquitous. This suggests that the country's 


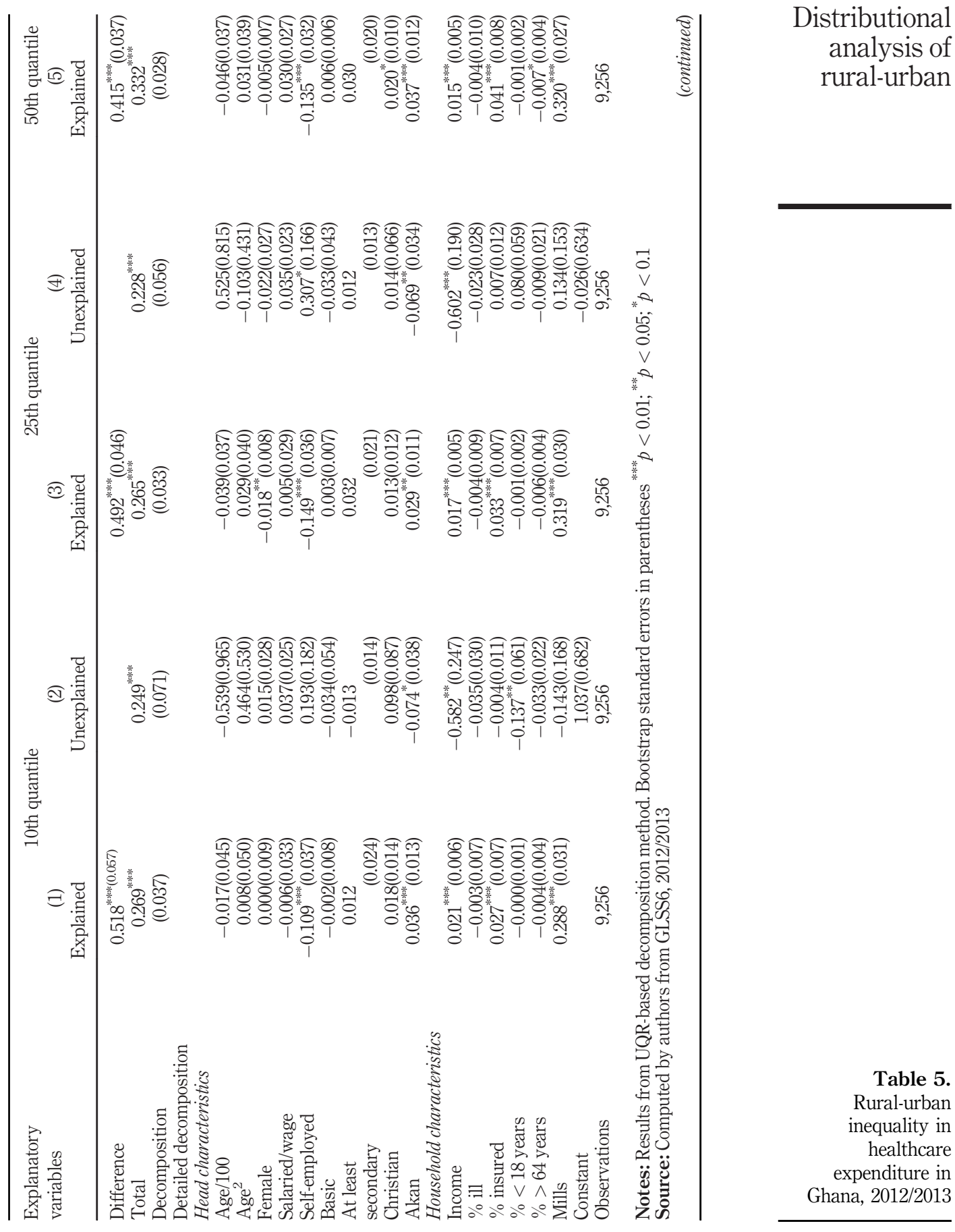
Distributional analysis of rural-urban




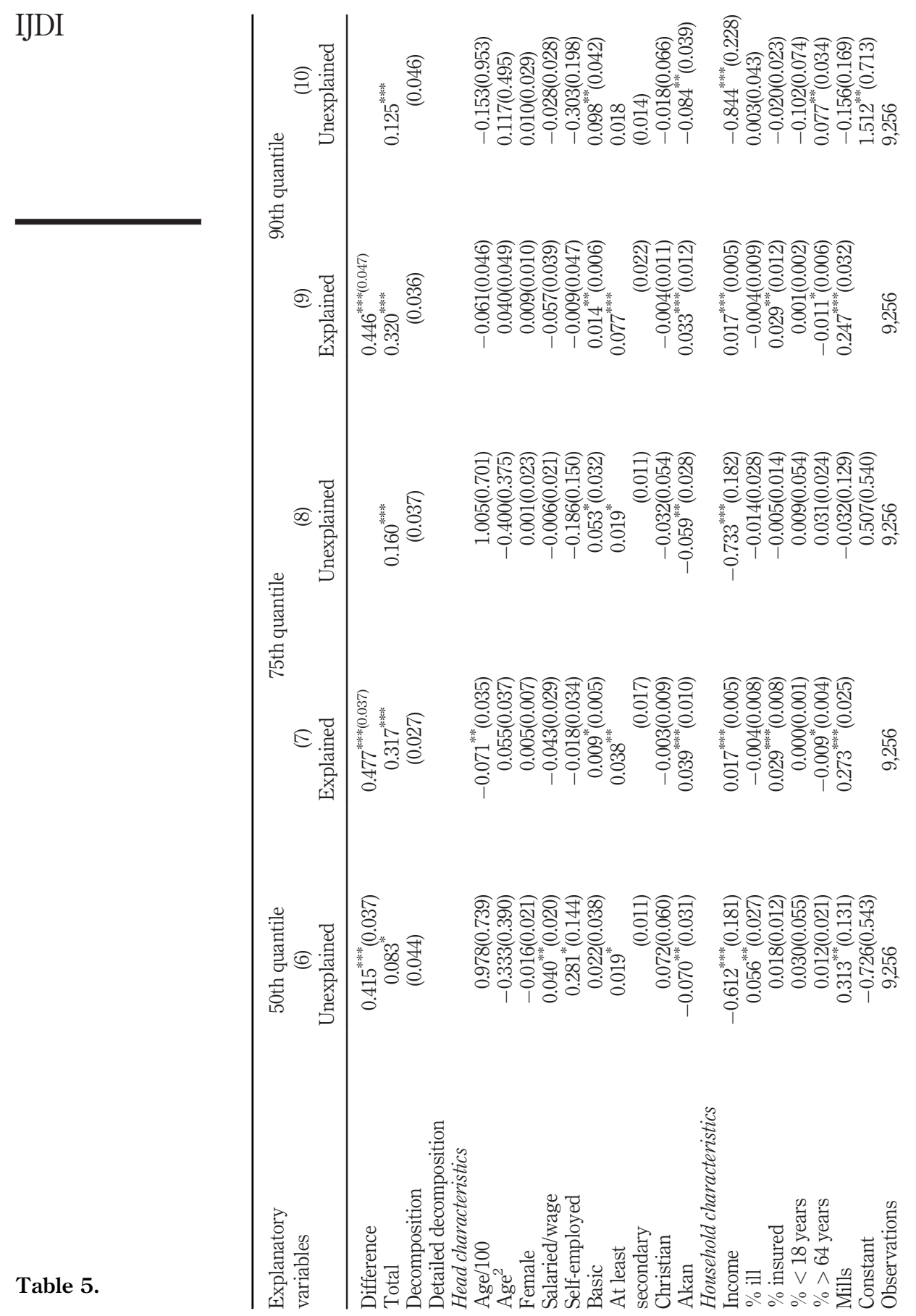




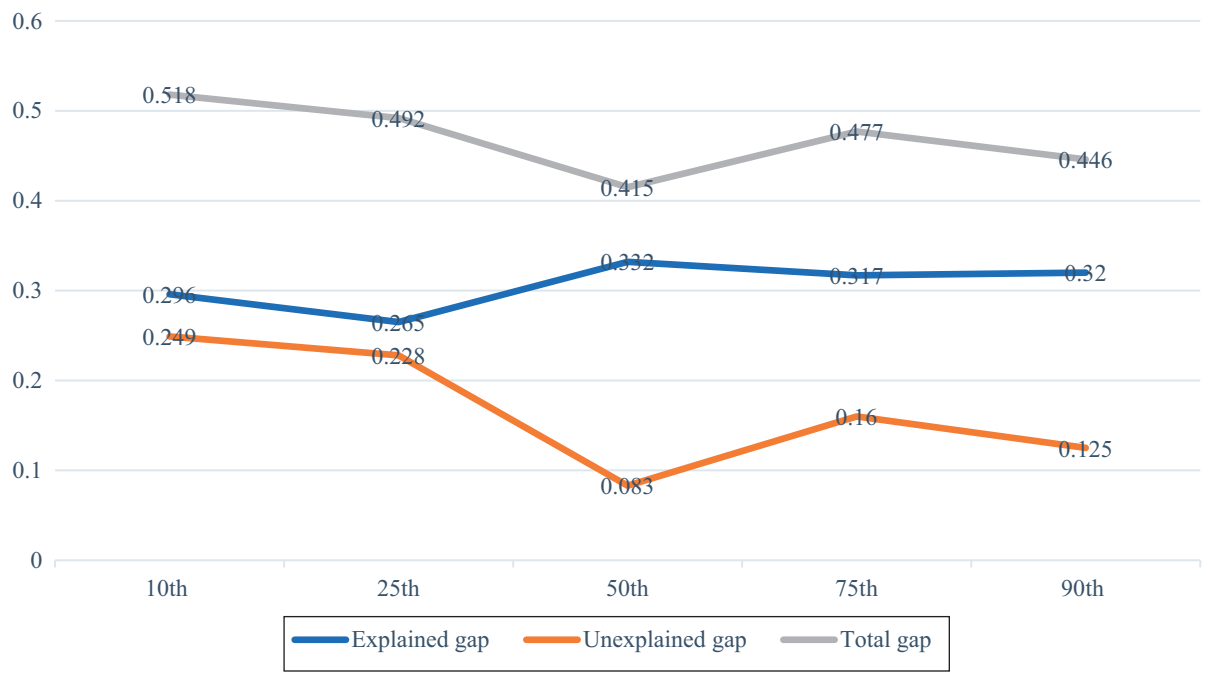

Distributional analysis of rural-urban

Source: Computed by authors from GLSS 6, 2012/2013

Figure 2.

Distribution of the rural-urban household healthcare expenditure gap, 2012/2013

growth has not been equitably distributed. The rural sector increasingly accounts for the biggest share of the extremely poor population (Ghana Statistical Service, 2018). More so, the institution of the NHIS to protect the poor, most of whom reside in the rural areas, from financial catastrophes associated with healthcare consumption has been pro-urban (Akazili et al., 2014). The informal fees charged at NHIS accredited facilities further discourage participation in the NHIS especially by the poor. We show that efforts to narrow the ruralurban household healthcare expenditure gap should be directed towards minimising the ruralurban gaps in household income per capita and enrolment on health insurance policies.

Other significant variables including self-employment and formal education are reported to differ on how they affect the rural-urban healthcare expenditure gap along the selected quantiles. In particular, albeit self-employment is found to have a significant $(\phi<0.01)$ and negative effect on the gap in the 10th, 25th and 50th quantiles, formal education is reported to have a significant $(\phi<0.05)$ and positive effect on the gap in the higher quantiles (75th and 90th) only. In regard to policy, policymakers in attempts to alleviate and ultimately eradicate, the rural-urban household healthcare expenditure gap among Ghanaian households, which spend most on healthcare ought to consider reducing the rural-urban gaps in the attainment of formal education.

\section{Conclusion}

This paper attempts to provide a distributional analysis of the rural-urban healthcare expenditure differentials in Ghana. In particular, it investigates the differences in the determinants of household healthcare expenditure across space and along selected quantiles of healthcare expenditure. The rural-urban expenditure gap and its determinants along selected quantiles are also explored. Because equity in the access and use of healthcare resources is a global development agenda, policymakers ought to know these differences for effective policy.

Results from UQR indicate that individual-level variables including employment type, higher education and ethnicity are more important in explaining household healthcare expenditure differentials across space (rural vs urban) and along the selected quantiles compared to householdlevel characteristics. Besides, based on the UQR-based decomposition method, the study finds a 
positive health expenditure gap in favour of urban households. This gap is reported to be greatest among households in the lower quantiles. Further findings are that this gap is principally driven by rural-urban differences in household income per capita, percentage of household members enrolled on health insurance policies and ethnic affiliation.

We suggest that, as different factors affect household healthcare spending, targeted policies should be prioritised. Furthermore, to reduce rural-urban healthcare expenditure inequality, efforts must be geared towards narrowing the rural-urban differences in income per capita and enrolment on health insurance policies.

\section{Notes}

1. Following Heckman (1979) two-step approach.

2. Included both those who spent on healthcare and those who did not spend on healthcare.

3. The dominant ethnic group, accounting for more than $50 \%$ of the population.

\section{References}

Agyire-Tettey, F., Ackah, C.G. and Asuman, D. (2017), "An unconditional quantile regression-based decomposition of spatial welfare inequalities in Ghana", The Journal of Development Studies, Vol. 54 No. 3.

Akazili, J., Welaga, P., Bawah, A., Achana, F.S., Oduro, A., Awoonor-Williams, J.K., Williams, J.E., Aikins, M. and Phillips, J.F. (2014), "Is Ghana's pro-poor health insurance scheme really for the poor? Evidence from Northern Ghana”, BMC Health Services Research, Vol. 14 No. 1, pp. 637.

Alhassan, R., Nketiah-Amponsah, E. and Arhinful, D. (2016), "A review of the national health insurance scheme in Ghana: what are the sustainability threats and prospects?", PLoS One, Vol. 11 No. 11.

Anyanwu, J.C. and Erhijakpor, A.E.O. (2009), "Health expenditures and health outcomes in Africa", African Development Review, Vol. 21 No. 2, pp. 401-434.

Arthur, E. and Oaikhenan, H.E. (2017), "The effects of health expenditure on health outcomes in SubSaharan Africa", African Development Review, Vol. 29 No. 3, pp. 524-536.

Aryeetey, G.C., Nonvignon, J., Amissah, C., Buckle, G. and Aikins, M. (2016a), "The effect of the national health insurance scheme (NHIS) on health service delivery in mission facilities in Ghana: a retrospective study", Globalization and Health, Vol. 12 No. 1, p. 1.

Aryeetey, G.C., Westeneng, J., Spaan, E., Jehu-Appiah, C. and Agyepong, I.A. (2016b), "Can health insurance protect against out-of-pocket and catastrophic expenditures and also support poverty reduction? Evidence from Ghana's national health insurance scheme", International Journal for Equity in Health, Vol. 15 No. 1.

Ashiabi, N., Nketiah-Amponsah, E. and Senadza, B. (2016), "The effect of health expenditure on selected maternal and child health outcomes in Sub-Saharan Africa”, International Journal of Social Economics, Vol. 43 No. 12, pp. 1386-1399.

Azam, M. (2017), “Are Urban-Rural welfare differences growing in India?”, IZA DP No. 11174.

Bagnoli, L. (2017), "Does national health insurance improve children's health? National and regional evidence from Ghana", ECARES Working Papers, ECARES 2017-03.

Dixon, J., Tenkorang, E. and Luginaah, I. (2011), "Ghana's national health insurance scheme: helping the poor or leaving them behind? ", Environment and Planning C: Government and Policy, Vol. 29 No. 6, pp. 1102-1115.

Donfouet, H.P., Makaudze, E., Mahieu, P.A. and Malin, E. (2011), "The determinants of the willingnessto-pay for community-based prepayment scheme in rural Cameroon", International Journal of Health Care Finance and Economics, Vol. 11 No. 3, pp. 209-220. 
Fortin, N., Lemieux, T. and Firpo, S. (2011), "Decomposition methods in economics", Handbook of Labour Economics, Vol. 4, pp. 1-102.

Ghana Statistical Service (2014), "Ghana living standards survey”, Report of Sixth Round (GLSS6), Ghana Statistical Service, Accra.

Ghana Statistical Service (2018), "Poverty trends in Ghana”, 2005-2017. Accra.

Go, D., Nikitin, D., Wang, X. and Zou, H. (2007), "Poverty and inequality in Sub-Saharan Africa: literature survey and empirical assessment", Annals of Economics and Finance, Vol. 8 No. 2, pp. 251-304.

Hartley, D.A. (2004), "Rural health disparities, population health, and rural culture", American Journal of Public Health, Vol. 94 No. 10, pp. 1675-1678.

Heckman, J. (1979), "Sample selection bias as a specification error", Econometrica, Vol. 47 No. 1, pp. 153-161.

Jehu-Appiah, C., Aryeetey, G., Spaan, E., de Hoop, T. and Agyepong, I., R., B. (2011), "Equity aspects of the national health insurance scheme in Ghana: who is enrolling, who is not and why?", Social Science and Medicine, Vol. 72 No. 2, pp. 157-165.

Lee, W.C., Jiang, L., Phillips, C.D. and Ohsfeldt, R.L. (2014), "Rural-Urban differences in health care expenditures: empirical data from US households", Advances in Public Health, Vol. 2014.

Mahumud, R.A., Sarker, A.R., Sultana, M., Islam, Z., Khan, J. and Morton, A. (2017), "Distribution and determinants of out-of-pocket healthcare expenditures in Bangladesh", Journal of Preventive Medicine and Public Health, Vol. 50 No. 2, pp. 91-99.

Malik, A.M. and Syed, S.I. (2012), "Socio-economic determinants of household out-of-pocket payments on healthcare in Pakistan", International Journal for Equity in Health, No. 51, p. 11.

Molla, A.A., Chi, C. and Mondaca, A.L. (2017), "Predictors of high out-of-pocket healthcare expenditure: an analysis using Bangladesh household income and expenditure survey, 2010", BMC Health Services Research, Vol. 17 No. 1, p. 94.

Murthya, V.N. and Okunadeb, A.A. (2009), "The core determinants of health expenditure in the African context: Some econometric evidence for policy”, Health Policy, Vol. 91 No. 1, pp. 57-62.

Nguyen, B.T., Albrecht, J.W., Vroman, S.B. and Westbrook, M.D. (2007), "A quantile regression decomposition of urban-rural inequality in Vietnam", Journal of Development Economics, Vol. 83 No. 2, pp. 466-490.

Nketiah-Amponsah, E. and Arthur, E. (2013), "Choice of delivery facility among expectant mothers in Ghana: does access to health insurance matter?”, Journal of Health Management, Vol. 15 No. 4 , pp. 509-524.

Novignon, J., Nonvignon, J. and Arthur, E. (2015), "Health status and labour force participation in Sub-Saharan Africa: a dynamic panel data analysis", African Development Review, Vol. 27 No. 1, pp. 14-26.

Novignon, J., Olakojo, S.A. and Nonvignon, J. (2012), "The effects of public and private health care expenditure on health status in Sub-Saharan Africa: new evidence from panel data analysis", Health Economics Review, Vol. 2 No. 1, p. 22.

O'Donnell, O. (2007), "Access to health care in developing countries: breaking down demand side barriers”, Cadernos de Saúde PúBlica, Vol. 23, pp. 2820-2834.

Olasehinde, N. and Olaniyan, O. (2017), "Determinants of household health expenditure in Nigeria", International Journal of Social Economics, Vol. 44 No. 12, pp. 1694-1709.

Onwujekwe, O.E., Uzochukwu, B.S., Obikeze, E.N., Okoronkwo, I., Ochonma, O.G., Onoka, C.A., Madubuko, G. and Okoli, C. (2010), "Investigating determinants of out-of-pocket spending and strategies for coping with payments for healthcare in southeast Nigeria", BMC Health Services Research, Vol. 10 No. 1.

Ottersen, T., Evans, D.B., Mossialos, E. and Røttingen, J.-A. (2017), "Global health financing towards 2030 and beyond”, Health Economics, Policy and Law, Vol. 12 No. 2, pp. 105-111.
Distributional analysis of rural-urban 
Owusu-Sekyere, E. and Bagah, D.A. (2014), "Towards a sustainable health care financing in Ghana: is the national health insurance the solution?”, Public Health Research, Vol. 4 No. 5, pp. 185-194.

Peters, D.H., Garg, A., Bloom, G., Walker, D.G., Brieger, W.R. and Rahman, M.H. (2008), "Poverty and access to health care in developing countries", Annals of the New York Academy of Sciences, Vol. 1136 No. 1, pp. 161-171.

Rous, J.J. and Hotchkiss, D.R. (2003), "Estimation of the determinants of household health care expenditures in Nepal with controls for endogenous illness and provider choice", Health Economics, Vol. 12 No. 6, pp. 431-451.

van der Wielen, N., Falkingham, J. and Channon, A.A. (2018), "Determinants of national health insurance enrolment in Ghana across the life course: are the results consistent between surveys? ", International Journal for Equity in Health, Vol. 17 No. 1, pp. 49.

World Health Organization (2010), Health Systems Financing - a Path to Universal Coverage, World Health Organization, Geneva.

Yildirim, J., Yilmaz, E. and Korucu, N. (2011), "The determinants of out-of-pocket payments: evidence from selected hospitals in Ankara”, Applied Economics Letters, Vol. 18 No. 12, pp. 1159-1162.

You, X. and Kobayashi, Y. (2011), "Determinants of out-of-pocket health expenditure in China", Applied Health Economics and Health Policy, Vol. 9 No. 1, p. 39-49.

Ziller, E.C., Coburn, A.F. and Yousefian, A.E. (2006), "Out-of-pocket health spending and the rural underinsured”, Health Affairs, Vol. 25 No. 6, pp. 1688-1699.

\section{Further readings}

Abeldaño, R.A. (2017), “Analysis of household expenditure on healthcare in Argentina, as a component of universal health coverage”, Ciência and Saúde Coletiva, Vol. 22 No. 5, pp. 1631-1640.

Chevarley, F.M., Owens, P.L., Zodet, M.W., Simpson, L.A., McCormick, M. and Dougherty, D. (2006), "Health care for children and youth in the United States: annual report on patterns of coverage, utilization, quality, and expenditures by a county-level of urban influence", Ambulatory Pediatrics, Vol. 6 No. 5, pp. 241-264.

Firpo, S., Fortin, N.M. and Lemieux, T. (2009), "Unconditional quantile regressions", Econometrica, Vol. 77 No. 3, pp. 953-973.

Hajizadeh, M. and Nghiem, H.S. (2011), "Out-of-pocket expenditures for hospital care in Iran: who is at risk of incurring catastrophic payments? ", International Journal of Health Care Finance and Economics, Vol. 11 No. 4, pp. 267-285.

West, A.N. and Weeks, W.B. (2009), "Health care expenditures for urban and rural veterans in veterans health administration care", Health Services Research, Vol. 44 No. 5p1, pp. 1718-1734.

\section{Corresponding author}

Bernardin Senadza can be contacted at: bsenadza@ug.edu.gh 
Appendix A

Distributional analysis of

Explanatory variables

Coefficient

Linearised

rural-urban

Standard error

Head characteristics

Age/100

$\mathrm{Age}^{2}$

Female

Salaried/wage

Self-employed

Basic

At least secondary

Ethnicity

Religion

Household characteristics

Income

$\%$ ill

$\%$ insured

$\%<18$ years

$\%>64$ years

Exclusion principle variables

North

Forest

Coastal

GAMA

Household size

Household size square

Constant

Observations

$F$-statistic

$F$-adjusted mean residual test

\begin{tabular}{cc}
1.038 & 0.828 \\
-1.001 & 0.822 \\
-0.065 & 0.054 \\
-0.002 & 0.109 \\
$0.349^{* * * * *}$ & 0.113 \\
$-0.129^{* * * *}$ & 0.060 \\
$-0.179^{* * *}$ & 0.083 \\
0.107 & 0.075 \\
-0.044 & 0.070 \\
& \\
$0.063^{* * * *}$ & 0.018 \\
$0.010^{* * * * *}$ & 0.001 \\
$0.004^{* * *}$ & 0.002 \\
$0.004^{* * *}$ & 0.002 \\
0.002 & 0.001 \\
& \\
$-0.300^{* *}$ & 0.174 \\
-0.186 & 0.159 \\
$-0.329^{* *}$ & 0.195 \\
$-0.343^{* * * *}$ & 0.210 \\
$0.214^{* * * *}$ & 0.023 \\
$-0.009^{* * * *}$ & 0.002 \\
$-1.158^{* * *}$ & 0.272 \\
\hline 14 &
\end{tabular}

16,514

$13.45(0.000)$

$0.521(0.860)$
0.828

0.822

0.109

0.113

0.060

0.083

0.075

0.070

0.018

0.001

0.002

0.002

0.174

0.159

0.195

0.210

0.002

0.272

Table A1.

Logistic regression:

determinants of household healthcare expenditure, 2012/

Notes: ${ }^{* * * *} p<0.01 ;{ }^{* * *} p<0.05 ;{ }^{*} p<0.1$

For instructions on how to order reprints of this article, please visit our website: 